\title{
The cyclic-fatigue behaviour of an epoxy polymer modified with micron-rubber and nano-silica particles
}

\author{
C. M. Manjunatha $\cdot$ A. C. Taylor $\cdot$ A. J. Kinloch . \\ S. Sprenger
}

Received: 30 April 2009/Accepted: 1 June 2009/Published online: 18 June 2009

(C) Springer Science+Business Media, LLC 2009

\section{Introduction}

Fibre-reinforced plastic (FRP) composites are widely used in ship hull, airframe and wind turbine structural applications where they are subjected to various types of constant and variable amplitude cyclic-fatigue loads. Hence, fatiguedurability is one of the important requirements for such composite materials. These FRPs, generally, contain continuous fibres of carbon or glass reinforced in a thermosetting epoxy-polymer matrix. The epoxy polymers are amorphous and highly cross-linked materials, because of which they have many useful structural properties such as a high modulus and failure strength, good creep resistance, good thermal properties, etc. However, they are relatively brittle and have poor resistance to crack initiation and growth. This, in turn, may adversely affect the overall performance of the FRPs under static and cyclic-fatigue loads.

The addition of micron-rubber and nano-silica particles in the epoxy polymer has been shown to impart significant improvements in the mechanical properties of epoxies and FRPs [1-7]. However, investigations related to cyclicfatigue behaviour on particle-modified epoxies are rather

C. M. Manjunatha $(\bowtie) \cdot$ A. C. Taylor · A. J. Kinloch Department of Mechanical Engineering, Imperial College London, South Kensington Campus, London SW7 2AZ, UK e-mail: manjucm@nal.res.in

A. C. Taylor

e-mail: a.c.taylor@imperial.ac.uk

A. J. Kinloch

e-mail: a.kinloch@imperial.ac.uk

S. Sprenger

Nanoresins AG, Charlottenburger Str. 9, 21502 Geesthacht, Germany

e-mail: stephan.sprenger@nanoresins.com limited and, in particular, fatigue studies on 'hybrid' epoxies containing both types of these particles are not available. This letter addresses the tensile fatigue behaviour of micron-rubber and nano-silica particle modified epoxy polymers, and describes some very novel and exciting observations.

\section{Experimental}

The materials were based upon a single-component hotcured epoxy formulation. The epoxy resin was standard diglycidyl ether of bis-phenol A (DGEBA) with an epoxide equivalent weight (EEW) of 185 g/eq, 'LY556' supplied by Huntsman, UK. The reactive liquid carboxyl-terminated butadiene-acrylonitrile (CTBN) rubber (which gives rise to micrometre-sized particles upon curing) was obtained as a CTBN-epoxy adduct with a rubber concentration of $40 \mathrm{wt} \%$ in DGEBA epoxy resin, namely 'Albipox 1000' (EEW = $330 \mathrm{~g} / \mathrm{eq})$ from Nanoresins, Germany. The silica $\left(\mathrm{SiO}_{2}\right)$ nano-particles were obtained at a concentration of $40 \mathrm{wt} \%$ in DGEBA epoxy resin (EEW = $295 \mathrm{~g} / \mathrm{eq}$ ) as 'Nanopox F400' from Nanoresins. The curing agent was an accelerated methylhexahydrophthalic acid anhydride, 'Albidur HE 600' $(\mathrm{AEW}=170 \mathrm{~g} / \mathrm{eq})$, also supplied by Nanoresins.

The DGEBA epoxy resin was mixed with the $\mathrm{SiO}_{2}-$ epoxy and/or the CTBN-epoxy adduct to give the required levels of added nano-silica and/or CTBN rubber. The stoichiometric amount of the curing agent was added to the mixture, stirred thoroughly and degassed at $50{ }^{\circ} \mathrm{C}$ and $-1 \mathrm{~atm}$. The resin mixture was then poured into a releasecoated steel mould. The filled mould was then placed in an oven and cured at $100{ }^{\circ} \mathrm{C}$ for $2 \mathrm{~h}$ and post-cured at $150{ }^{\circ} \mathrm{C}$ for $10 \mathrm{~h}$. Four different types of bulk epoxy polymer sheets were prepared viz., (a) neat epoxy (EP), (b) epoxy with 
9 wt\% CTBN rubber micro-particles (ER), (c) epoxy with $10 \mathrm{wt} \%$ silica nano-particles (ES) and, (d) a 'hybrid' epoxy containing both 9 wt\% CTBN rubber micro-particles and $10 \mathrm{wt} \%$ silica nano-particles (ERS).

An atomic force microscope with a 'multimode' scanning probe microscope from Veeco equipped with a ' $\mathrm{J}$ ' scanner and a 'Nanoscope IV' controller was used to study the microstructure of bulk epoxy materials. A smooth surface was first prepared by cutting samples using a microtome at room temperature. The scans were performed in tapping mode, using silicon probes.

The tensile properties of all the epoxy polymers were determined according to ASTM D638 test standard [8] specifications using 'dog-bone' shaped specimens, being $165 \mathrm{~mm}$ in length with a nominal gauge section of $10 \mathrm{~mm} \times 5 \mathrm{~mm}$. Tests were performed using a $100 \mathrm{kN}$ computer-controlled screw-driven test machine with a constant crosshead speed of $1 \mathrm{~mm} / \mathrm{min}$. An extensometer with a $25 \mathrm{~mm}$ gauge length was used to record the strains. Five replicate tests were conducted for each material and the average tensile properties which were determined are shown in Table 1.

The cyclic-fatigue test specimens, similar in size and shape to the tensile specimens, were machined from the epoxy sheets. The sharp edges of the test specimen were gently polished with emery paper and rounded off to avoid stress concentration effects. The constant-amplitude, stresscontrolled, cyclic-fatigue tests were conducted using a $25 \mathrm{kN}$ computer-controlled servo-hydraulic test machine with the following fatigue test parameters: stress ratio $(R)$, $\sigma_{\min } / \sigma_{\max }=0.1$, a sinusoidal waveform and a frequency, $v=1 \mathrm{~Hz}$. The fracture surfaces of the fatigue-tested specimens were sputter-coated with a thin layer of gold/ platinum, and then observed using a high-resolution scanning electron microscope fitted with a field-emission gun emitter (termed 'FEG-SEM').

\section{Results and discussion}

The tapping-mode atomic force microscopy (AFM) phase images of the various particle-modified epoxy polymers are shown in Fig. 1. The rubber particles were evenly distributed and had an average diameter of about $0.5-1.0 \mu \mathrm{m}$ in both the ER and ERS polymers. The silica particles were about $20 \mathrm{~nm}$ in diameter and were evenly distributed in the ES polymer, but they were somewhat agglomerated to give a 'necklace-type' structure, with an average width of about $1.0-1.5 \mu \mathrm{m}$, in the ERS polymer.

The constant-amplitude, tensile fatigue test results obtained for the neat and various particle-modified epoxy polymers at a stress ratio, $R=0.1$ are shown in Fig. 2. It may be clearly seen that for a given maximum stress level, and over the entire range of stress levels investigated, the fatigue lives of all the particle-modified epoxies are longer than that of the neat epoxy. The fatigue life enhancements recorded for the ER polymer (i.e. containing micron-rubber alone) and the ES polymer (i.e. containing nano-silica alone) were almost similar. Further, the fatigue lives of both the ER and ES polymers are about 3-4 times longer than that of the neat epoxy (EP). The presence of both micron-rubber and nano-silica particles in the ERS 'hybrid' polymer appears to further enhance the fatigue life significantly, i.e. by a factor of about 6-10 times compared to
Table 1 Tensile properties of the neat and modified epoxy polymers

\begin{tabular}{llllll}
\hline Materials & Formulation & & & Tensile properties \\
\cline { 2 - 3 } \cline { 5 - 6 } & $\begin{array}{l}\mathrm{CTBN} \\
(\mathrm{wt} \%)\end{array}$ & $\begin{array}{l}\mathrm{SiO}_{2} \\
(\mathrm{wt} \%)\end{array}$ & & $\begin{array}{l}\text { Ultimate tensile strength, } \\
\sigma_{\text {UTS }}(\mathrm{MPa})\end{array}$ & $\begin{array}{l}\text { Tensile modulus, } \\
E(\mathrm{GPa})\end{array}$ \\
\hline $\mathrm{EP}$ & 0 & 0 & & $73.4 \pm 1.6$ & $2.62 \pm 0.05$ \\
$\mathrm{ER}$ & 9 & 0 & $65.1 \pm 1.5$ & $2.11 \pm 0.03$ \\
ES & 0 & 10 & & $86.9 \pm 1.3$ & $3.07 \pm 0.03$ \\
ERS & 9 & 10 & $64.4 \pm 0.4$ & $2.35 \pm 0.06$ \\
\hline
\end{tabular}

Fig. 1 The tapping-mode atomic force microscopy (AFM) phase images of the particlemodified epoxy polymers: a ER; b ES; c ERS
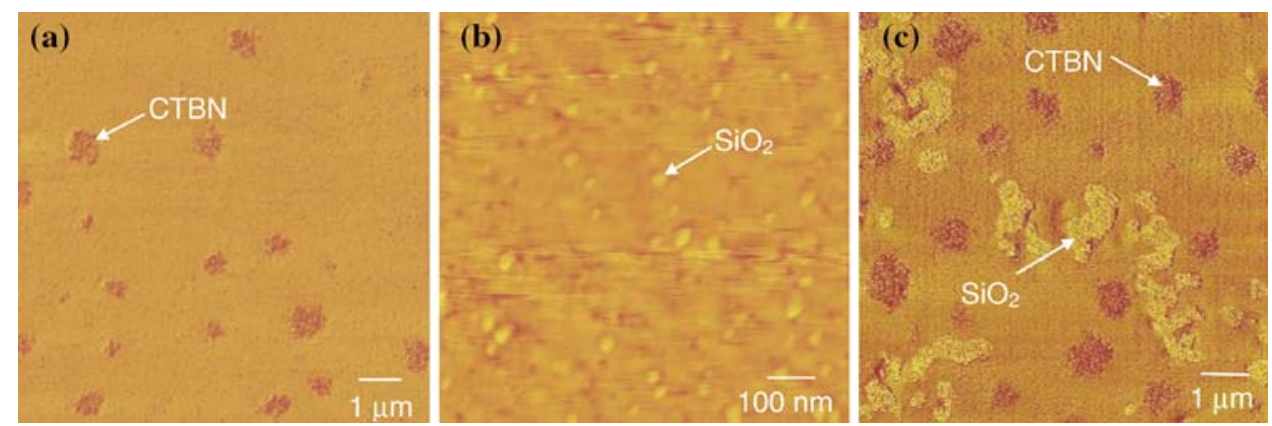


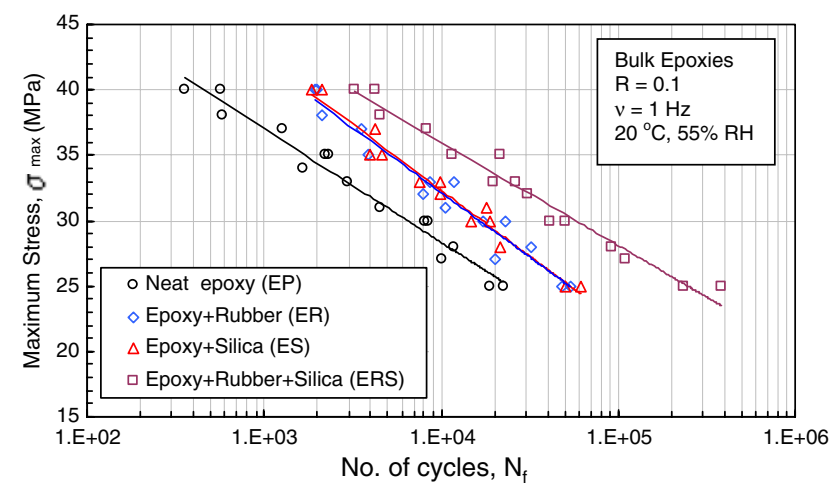

Fig. 2 Stress versus lifetime (S-N) curves of the epoxy polymers

that of neat epoxy polymer (EP). The fatigue life enhancement in the ERS polymer was particularly pronounced at the low stress ranges, which is very noteworthy for obtaining extended fatigue lives from components manufactured using such epoxy polymers. It is noteworthy that these results are in agreement with other studies where nano-modified epoxy polymers based upon carbon nano-fibres and nano-silicates have also been shown to exhibit higher fatigue lives, compared to their respective neat epoxy polymers $[9,10]$.

The high-resolution scanning electron microscopy (FEG-SEM) images of the fatigue fracture surfaces of all the epoxy polymers are shown in Fig. 3. The neat epoxy (EP) exhibited a relatively smooth fracture surface when compared to all other particle-modified epoxies and it is devoid of any indications of large-scale plastic deformation (Fig. 3a). The ER epoxy fracture surface shows clear indications of the cavitated rubber micro-particles and plastic deformation, via void growth, of the surrounding epoxy polymer (Fig. 3b). A similar toughening mechanism has been previously proposed to explain the reduced fatigue crack propagation rates observed in a rubber-particle modified epoxy polymer [11].

The ES polymer exhibits a relatively rough fracture surface, which reveals the presence of voids (circled on the micrograph) which are created by the debonding of silica nano-particles followed by plastic void growth of the epoxy matrix (Fig. 3c and d). Indeed, the measured void
Fig. 3 The scanning electron micrographs of the fatigue fracture surface of the epoxy polymers (crack propagation is from left to right). a EP, $\sigma_{\max }=37 \mathrm{MPa}, N_{\mathrm{f}}=1283$ b ER, $\sigma_{\max }=37 \mathrm{MPa}$, $N_{\mathrm{f}}=3558 . \mathbf{c}, \mathbf{d} \mathrm{ES}, \sigma_{\max }=37$ $\mathrm{MPa}, N_{\mathrm{f}}=4230$. e, f ERS, $\sigma_{\max }=37 \mathrm{MPa}, N_{\mathrm{f}}=8246$
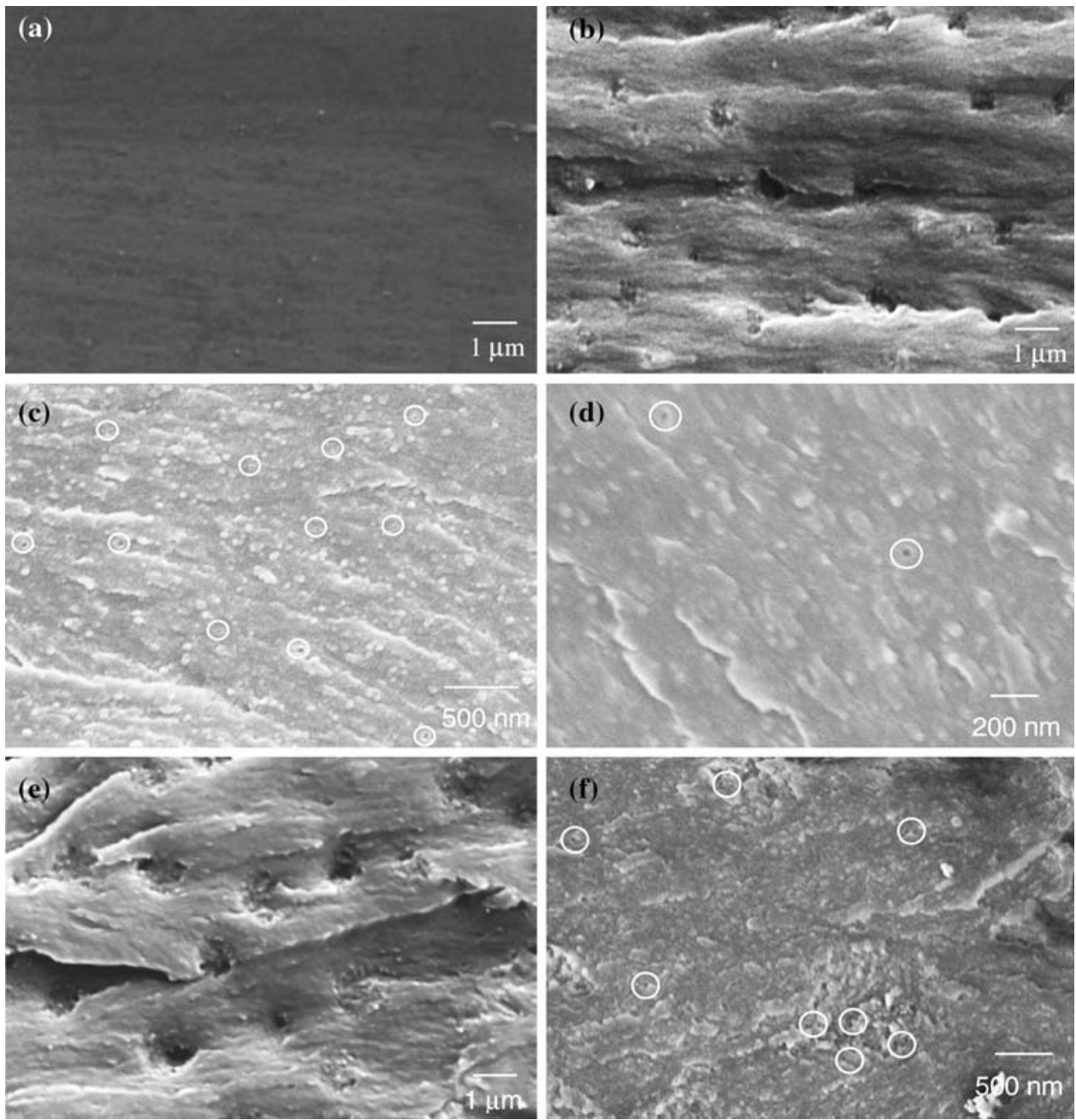
size was slightly higher than the average diameter of silica particles, revealing that plastic void growth had occurred during fatigue crack propagation. Such a particle debonding-plastic void growth mechanism has been previously observed in epoxy polymers containing nano-silica particles $[12,13]$. The ERS polymer shows indications of both the energy dissipating mechanisms being operative, i.e. (i) rubber cavitation-plastic void growth (Fig. 3e) and (ii) silica particle debonding-plastic void growth (Fig. 3f).

It is noteworthy that the initiation and propagation of matrix cracks and interlaminar delaminations are the dominant and progressive fatigue damage mechanisms in a quasi-isotropic lay-up FRP composite employing a typical brittle epoxy matrix $[14,15]$. Hence, the fatigue strength of such fibre reinforced composite might well be enhanced if the fatigue behaviour of the epoxy matrix is improved. Clearly, the present results show that the use of such particle-toughened epoxy polymers as matrix materials in FRPs could result in composites with improved fatigue behaviour. Indeed, we have recently observed that the matrix crack formation is suppressed, and the fatigue life is improved significantly, in GFRP composites using such particle-reinforced epoxies as the matrices [16].

\section{Conclusions}

Based on the results obtained in this investigation, it is clear that the presence of rubber micro-particles and silica nano-particles in the epoxy polymer enhance the cyclicfatigue life. The addition of either the $9 \mathrm{wt} \%$ CTBN rubber micro-particles or the $10 \mathrm{wt} \%$ silica nano-particles alone in the epoxy polymer has almost a similar beneficial effect on the cyclic-fatigue performance in that they enhance the fatigue life by a factor of about 3-4 times. Furthermore, the presence of both rubber micro-particles and silica nanoparticles, to give a 'hybrid' modified epoxy polymer, results in a significant enhancement of the fatigue life, by about 6-10 times when compared to neat epoxy polymer, particularly at the low stress range. These observations are of major significance in relation to our earlier findings. Since they demonstrate that the major improvements in the cyclic-fatigue performance for the epoxy polymers, reported in the present communication, may indeed explain the similar level of improvements in the cyclic-fatigue behaviour which were observed when these same epoxy polymers were used as matrices for FRPs, using continuous glass-fibre as the reinforcement [16].

Acknowledgements Dr. CM Manjunatha wishes to thank and acknowledge the UK-India Education and Research Initiative (UKIERI) for awarding the Research Fellowship and Dr. AR Upadhya, Director, National Aerospace Laboratories, Bangalore, India for permitting him to accept the Fellowship. Mr. J Sohn Lee is thanked for his assistance with the FEG-SEM work.

\section{References}

1. Kinloch AJ, Shaw SJ, Tod DA, Hunston DL (1983) Polymer 24(10): 1341

2. Yee AF, Pearson RA (1986) J Mater Sci 21(7):2462. doi:10.1007/ BF01114293

3. Kinloch AJ (2003) Mater Res Soc Bull 28(6):445

4. Ma J, Mo MS, Du XS, Rosso P, Friedrich K, Kuan HC (2008) Polymer 49(16):3510

5. Kinloch AJ, Mohammed RD, Taylor AC, Eger C, Sprenger S, Egan D (2005) J Mater Sci 40(18):5083. doi:10.1007/s10853005-1716-2

6. Kinloch AJ, Mohammed RD, Taylor AC, Sprenger S, Egan D (2006) J Mater Sci 41(15):5043. doi:10.1007/s10853-006-0130-8

7. Kinloch AJ, Masania K, Taylor AC, Sprenger S, Egan D (2008) J Mater Sci 43(3):1151. doi:10.1007/s10853-007-2390-3

8. American Society for Testing and Materials (2003) Standard test method for tensile properties of plastics, ASTM D638-01, Annual book of ASTM Standards, vol 8.02. American Society for Testing and Materials, PA

9. Zhou Y, Pervin F, Jeelani S, Mallick PK (2008) J Mater Proc Tech 198:445

10. Zhou Y, Rangari V, Mahfuz H, Jeelani S, Mallik PK (2005) Mater Sci Eng A 402:109

11. Azimi HR, Pearson RA, Hertzberg RW (1996) J Mater Sci 31(14):3777. doi:10.1007/BF00352793

12. Johnsen BB, Kinloch AJ, Mohammed RD, Taylor AC, Sprenger S (2007) Polymer 48(2):530

13. Blackman BRK, Kinloch AJ, Sohn Lee J, Taylor AC, Agarwal R, Schueneman G, Sprenger S (2007) J Mater Sci 42(16):7049. doi: 10.1007/s10853-007-1768-6

14. Case SW, Reifsnider KL (2003) In: Milne I, Ritchie RO, Karihaloo B (eds) Comprehensive structural integrity, vol 4, cyclic loading and fatigue, 1st edn. Elsevier Science, Amsterdam, p 405

15. Talreja R (1987) Fatigue of composite materials. Technomic, Lancaster, PA, USA

16. Manjunatha CM, Taylor AC, Kinloch AJ, Sprenger S (2009) J Mater Sci 44(1):342. doi:10.1007/s10853-008-3092-1 